\title{
Investigation of texture gradients of semi-finished products by neutrons and photons
}

\author{
Heinz-Günter Brokmeier ${ }^{1, a}$, Christian Randau ${ }^{2, b}$, Weimin Gan $^{3, c}$, \\ Michael Hofmann ${ }^{4, d}$, Thomas Lippmann ${ }^{3 e}$ and Norbert Schell ${ }^{3, f}$ \\ ${ }^{1}$ Clausthal University of Technology, Agricolastr. 2, 38678 Clausthal-Zellerfeld, Germany \\ ${ }^{2}$ Clausthal University of Technology, Outstation at FRM-II, Lichtenbergstraße 1, 85748 Garching, \\ Germany \\ ${ }^{3}$ Helmholtz Zentrum Geesthacht, Max-Planck-Strasse 1, D-21502 Geesthacht, Germany \\ ${ }^{4}$ Forschungs-Neutronenquelle Heinz Maier-Leibnitz (FRM-II), Lichtenbergstraße 1, 85748 \\ Garching Germany \\ aheinz-guenter.brokmeier@tu-clausthal.de, ${ }^{\text {b }}$ christian.randau@frm2.tum.de, ${ }^{c}$ weimin.gan@hzg.de, \\ dmichael.hofmann@frm2.tum.de, ${ }^{\mathrm{T}}$ Thomas.Lippmann@hzg.de, ${ }^{\mathrm{f}}$ norbert.schell@hzg.de,
}

Keywords: texture gradient, neutron, synchrotron radiation, semi finished products

\begin{abstract}
Texture gradients are present in most samples, which are due to materials processing. Standard methods to evaluate texture gradients are based on the cut of samples, such as the X-ray investigation of surface textures against the texture inside a sheet. Bulk textures itself averaging over the whole sheet thickness are analysed by thermal neutrons. Both thermal neutrons and photons with high energies allow investigations non-destructively. The beam port Stress-Spec at the Forschungs-Neutronenquelle Heinz Maier-Leibnitz (FRM II) at Garching/Germany is equipped with a robot system based on a RX160 Stäubli robot, a Laser Tracker and a heavy basement. Samples up to $30 \mathrm{~kg}$ can be investigated. Main restrictions are the available neutron flux, the detector efficiency and the detector size. Thus, the gauge volume is restricted to $1 \times 1 \times 1 \mathrm{~mm}$ for ideal scattering conditions to measure in acceptable time scale. Photons with up to $200 \mathrm{keV}$ are known as high brilliant and high intense beam with similar penetration power than thermal neutrons. A typical set up of a high energy beamline for texture gradient investigations works without an Eulerian cradle so that restrictions in handling large sample are of less importance. The HZG materials science beamlines at Doris III and Petra III (Harwi-II@DorisIII and HEMS@PetraIII) are equipped with massif units for sample rotation and $\mathrm{x}-$, $\mathrm{y}$ - and $\mathrm{z}$ - scanning for samples and additional equipments up to $200 \mathrm{~kg}$. Compared to thermal neutrons, which work with wavelengths between $1 \AA-2.5 \AA$, the wavelength of high energy photons is small $(0.05 \AA-0.20 \AA)$. That leads on one hand to low scattering angles $\left(1^{\circ}-10^{\circ}\right)$ and on the other hand to an anisotropic ellipsoidal gauge volume. The local resolution of the synchrotron beam is much better than for thermal neutrons.

In both methods corrections for constant gauge volume during pole figure scanning and for anisotropic absorption are of great importance.

\section{Introduction}

Thermal neutrons as well as high energy photons are well-known for their high penetration power that both radiations are excellent looking deep inside matter. While neutrons can penetrate in general deeply the penetration power of photons depend strongly on the photon energy. In the case of energies of about 100-150keV penetrations depth of photons is in the same order as for neurons.

Neutron diffraction is much older than synchrotron diffraction and well established for many kinds of investigations in materials science [1]. For crystallographic texture investigation neutrons are favoured for bulk properties [2], while local studies are more related to residual stress profiles [3]. High energy photons with excellent brilliance are a heavily growing field in any kind of fast in situ experimentation as well as for gradient investigations (phase distribution, textures, stress profile, microstrains) with rather small gauge volume [1].
\end{abstract}


Semi finished products are defined as group of materials with wide spread of sample geometries. As shown in fig. 1, the sample geometry can be rather complicated and sample dimensions are in general in the $\mathrm{cm}$ range. Fig. 1a is a part of a $\mathrm{Nb}$-cavity with a visible failure of $5 \mathrm{~cm}$ length. Intense investigations were carried out to join different materials (laser beam welding, friction welding, friction stir welding), which can be characterized by neutrons and photons for stress profiles, texture gradients and phase developments. In fig. 1b a friction welded steel-steel sample of $10 \mathrm{~mm}$ diameter was shown. Fig. 1c shows a steel shaft positioned in an Eulerian cradle type Huber 512. This example shows clearly the restriction of an Eulerian cradle based instrument in sample rotation and sample tilt as well as movements in $\mathrm{x}$-, $\mathrm{y}$ - and $\mathrm{z}$-direction.

a

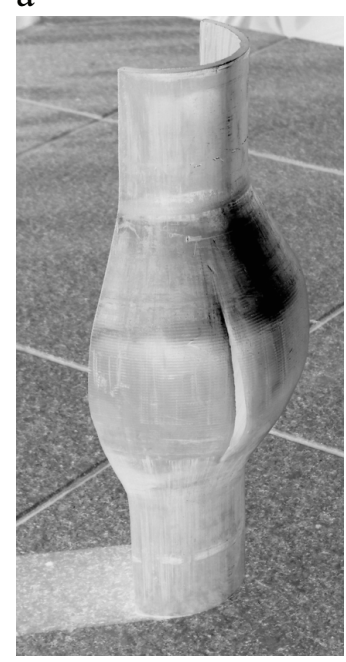

b

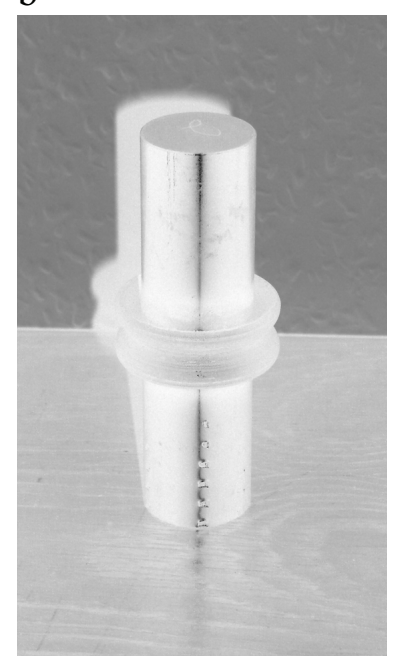

c



d

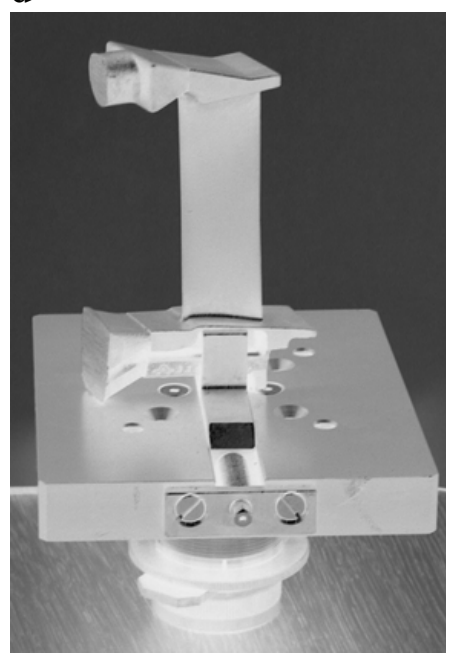

Fig.1: Examples of semi finished products with complex sample geometry

a) part of Nb-cavity; b) friction welded steel-steel; c) steel shaft;d) technical Ti example

\section{Basic assumptions}

Texture gradient investigations are always a compromise between the gauge volume needed for an interpretation and the grain statistics for sufficient quantitative texture calculations. Means, on one hand the gauge volume must be representative for texture and microstructure variations and on the other hand about $10^{6}$ grains should take part on the scattering. In fig. 2 the microstructure of a turbine blade is showing the gradient in this sample.

Due to the typical procedure to measure pole figures one has to tilt and rotate the sample. In the case of standard pole figure measurements one uses equal angular scans with $5^{\circ}$ tilt angle and $3.6^{\circ}$ or $5^{\circ}$ rotation angle. During pole figure measurement the gauge volume should be more or less constant. The gauge volume can be defined by slits systems of the incoming and the scattered beam. For both radiations and different detector types (finger detector, area detector) slit systems are available. For neutron diffraction radial collimators in front of area detectors and for synchrotron radiation conical slits can be used [4]. Nevertheless, one can estimate that rotation and tilt of the samples, shown in fig. 1 and fig. 2, will result firstly in anisotropic absorption or secondly that only incomplete pole figures with irregular distribution of pole figure points can be obtained. 


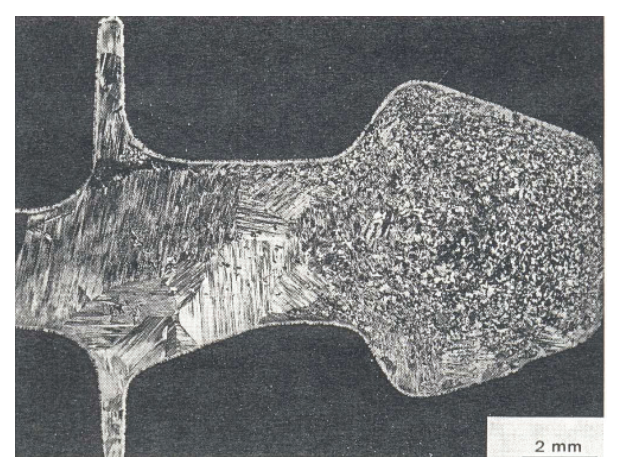

Fig.2: Cross section of a turbine blade with microstructure variation

A basic difference between thermal neutrons and high energy X-rays is the wavelength. In the case of thermal neutrons the wavelength is in between $1 \AA$ and $2.5 \AA$, which is quite similar to laboratory X-ray tubes ( $\mathrm{Mo} \mathrm{K} \alpha$; $\mathrm{Cu} \mathrm{K} \alpha$; $\mathrm{Co} \mathrm{K} \alpha$ and $\mathrm{Cr} \mathrm{K} \alpha$ ). For local measurements by neutron diffraction the so called '90degree arrangement' is favoured shown in fig. 3a. This geometry results in a cubic gauge volume which is relatively constant during rotation and tilt. This measurement is standard for residual stress analysis even of large components [3]. Hard X-rays with energies between $50 \mathrm{keV}$ and $200 \mathrm{keV}$ have wavelength between $0.248 \AA-0,062 \AA$ that results in comparably low scattering angles of $2 \theta<10^{\circ}$. The gauge volume is very anisotropic but much smaller than the typical neutron gauge volume (fig. $3 \mathrm{~b}$ ). One can see clearly on one hand that rotation and tilt needs a homogenous area of grain orientation and on the other hand that a precise scanning along gradients (severe plastic deformed materials, welded samples, pipe walls) is possible.

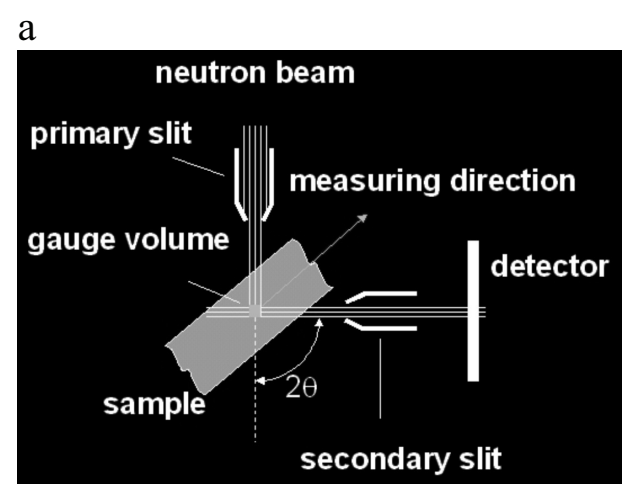

b synchrotron beam

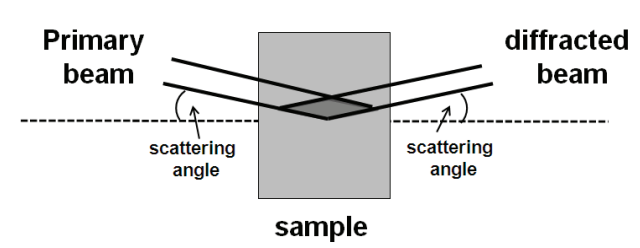

Fig.3: Gauge volume for different scattering angles

a) $90^{\circ}$ angle - neutron diffraction; b) low scattering angle - synchrotron diffraction

\section{Neutron diffractometer Stress Spec and examples}

The beam port Stress-Spec at the Forschungs-Neutronenquelle Heinz Maier-Leibnitz (FRM II) at Garching/Germany is designed as materials science diffractometer. Stress-Spec is a multipurpose instrument and combines the options for crystallographic texture investigations [5], residual stress analysis [6], phase analysis and microstrain studies. Consequently, the instrument has to be very flexible particular in choosing wavelength and set-up details. For instance, to combine the need for pole figure measurement and precise $\mathrm{d}$-value determination the monochromator take off angle can be varied continuously between $21^{\circ}$ and $42^{\circ}$ which means a continuous, fast and flexible opening of shielding of about $42^{\circ}-84^{\circ}$. This allows to set up the $90^{\circ}$ scattering position as shown in fig. $3 \mathrm{a}$ using Ge bent Si or pyrolytic graphite as monochromator $(0.8 \AA-3 \AA)$ for most materials.

An area detector of $300 \times 300 \mathrm{~mm}$ leads to simultaneous information of some reflections and on a part of the Debye-Scherrer rings, which speed up the pole figure measurement. In fig. 4 an area detector image of an Al-Mg composite is shown and the calculated diffraction pattern using the software package STECA [7] using the mathematics of Bunge and Klein [8]. Quality of the 
measurement as well as the software package allow to get reflex intensity pole figures (texture), reflex position pole figures (macrostrain) and reflex broadening pole figures (microstrain pole figures) simultaneously.
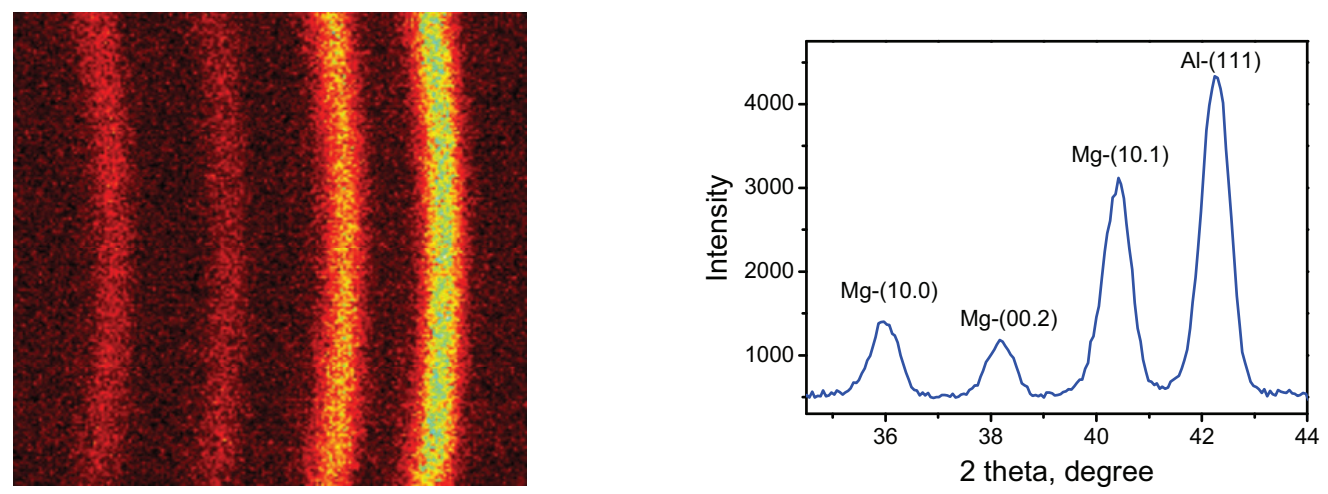

Fig.4: Area detector image with four reflections and calculated diagram

In the case of small samples the Eulerian cradle can be used for the investigation of semi finshed products. Stress Spec is equipped with a robot system based on a RX160 Stäubli robot, a Laser Tracker and a heavy basement that larger samples up to $30 \mathrm{~kg}$ can be handled easily. The Eulerian cradle arrangement has been used successfully at TEX-2 the FRG-1 texture diffractometer at Geesthacht/Germany [9] and recently for texture gradient investigations of a bonelike extrudate [10]. In fig. 5 the robot mounted on the basement (total weight of 2ton) and two examples are shown. Firstly, a combined analysis of stress profile and texture gradient of a friction welded sample (Al7020 with 316 steel, both $20 \mathrm{~mm} \varnothing$ ) was performed. The gauge volume was $1 \times 1 \mathrm{~mm}$ for strain measurements and $2 \times 2 \mathrm{~mm}$ for pole figure measurement to save time. Secondly, a $\mathrm{Cu}$-ring with an outer diameter of $140 \mathrm{~mm}$ was measured to analyse the texture inhomogeneity around the perimeter. All measurements can be done in step-scan mode or in continuous mode during sample rotation.
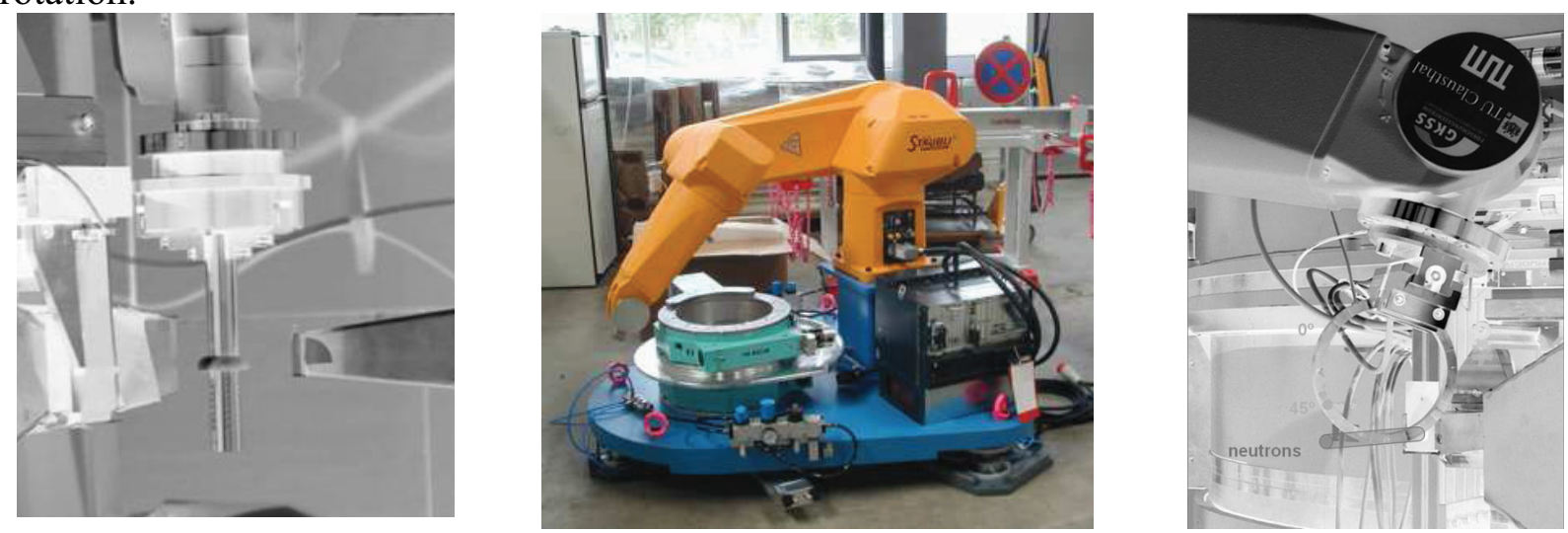

Fig.5: Stäubli RX160 (middle) with mounted samples (friction weld - left; Cu-ring - right)

In the case of semi-finished product and texture gradient measurements it is essential to correct for absorption and for constant volume. As an example (111) and (220) pole figures of the $\mathrm{Cu}$ ring measurement is shown in fig. 6 . For both corrections the sample shape has to be known to calculate the beam path of the incoming and the scattered beam for any pole figure point. Stress-Spec is equipped with a laser scanning system to determine the sample geometry, to define the scanning matrix and the beam path for any measurement position. It has to be noticed that the correction matrix varies for any sample position and for any Bragg-angle (different pole figure). This measurement is as long as the pole figure measurement itself but can be done outside the neutron beam. 
(111) non-corrected

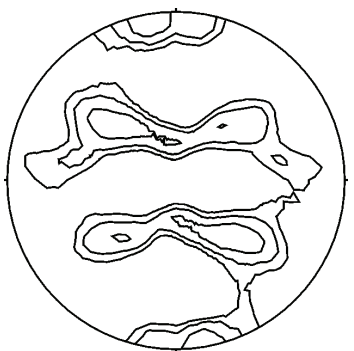

$\operatorname{Pmax}=4.8 \operatorname{mrd}$
(111) corrected



$\operatorname{Pmax}=4.5 \mathrm{mrd}$
(220) non-corrected

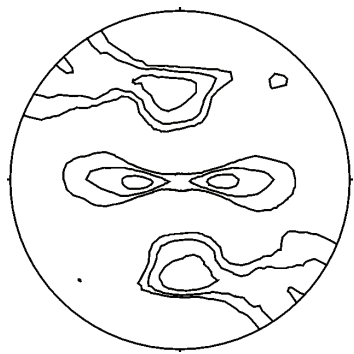

$\operatorname{Pmax}=5.3 \mathrm{mrd}$
(220) corrected

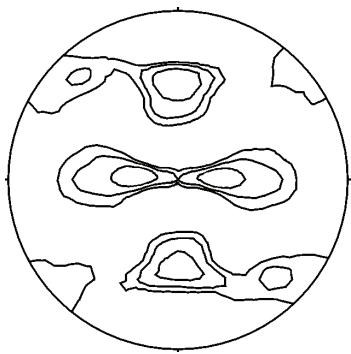

$\operatorname{Pmax}=5.2 \mathrm{mrd}$

Fig.6: Absorption and volume correction of $\mathrm{Cu}$-ring pole figure measurements

\section{Photon diffractometers Harwi-II and HEMS and examples}

Photons with up to $200 \mathrm{keV}$ are known as high brilliant and high intense beam with similar penetration power than thermal neutrons. A typical set up as one part of a high energy beamline for texture gradient investigations works without an Eulerian cradle so that restrictions in handling large sample are of less importance (fig. 7). It has to be noticed that materials science beamlines combine a set of experimental stations which can easily be changed, such as tomography, standard diffraction, strain scanner unit and small angle scattering (Harwi II@Doris III). The HZG materials science beamlines at Doris III and Petra III (Harwi-II@DorisIII and HEMS@PetraIII) are equipped with massif units for sample rotation and $\mathrm{x}-$, $\mathrm{y}$ - and $\mathrm{z}$ - scanning for samples and additional equipments up to $200 \mathrm{~kg}$ (Harwi-II) and up to $1000 \mathrm{~kg}$ (HEMS). Nevertheless much smaller and lighter samples are common.

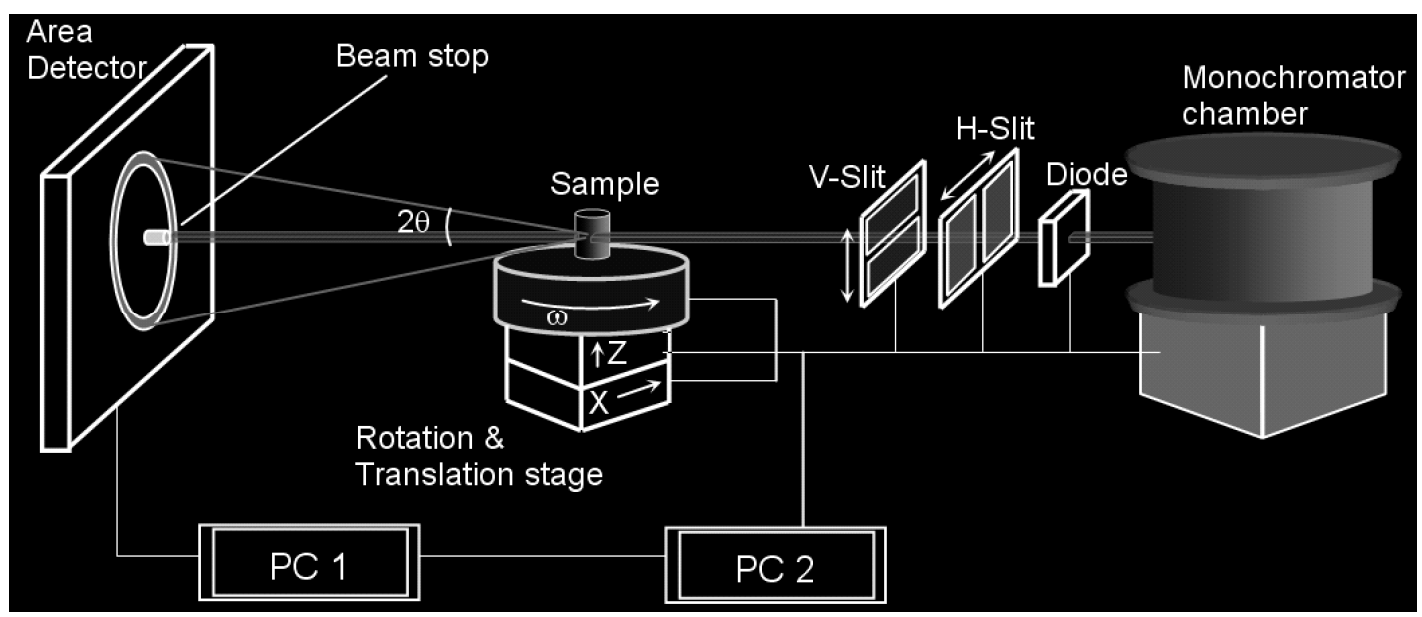

Fig.7: Typical set-up for texture measurement using hard X-rays.

The local resolution of synchrotron measurements is much better than for thermal neutrons. Main restriction in the gauge volume is the balance between grain statistics and texture gradient. Due to different characteristics of the storage rings Doris III and Petra III, Harwi-II is favoured for samples with medium grain size distributions and beam cross sections of $100 \mathrm{x} 100 \mu \mathrm{m}$ to $2 \mathrm{x} 4 \mathrm{~mm}$. The higher brilliant HEMS beamline is optimal for small grain size distributions and for single grain techniques, such as 3DXRD [11]. Using the volume method smallest beam size was $20 \times 50 \mu \mathrm{m}$ which is only useful in ultra fine grained materials (UGF's). 
According to the low scattering angle of hard X-rays one can get complete Debye Scherrer rings for a number of reflections using area detectors of about 300x300 mm size. Variable Sample to detector distance can be used to set up optimised conditions for many kinds of sample to deconvolve overlapped reflections. The generation of pole figures from a set of area detector data follows former work developed for the film technique in the nineteen forties [12, 13]. An area detector contains a set of Debye-Scherrer rings as shown in fig. 8a. The information of one DebyeScherrer ring in the stereographic projection (fig. 8b) has to be completed by sample rotation as shown in fig. 8c. The results of the $\mathrm{Al}$ (111) pole figure measured with $\Delta \omega=5^{\circ}$ were processed by STECA-program package. Measurements can be done by step scan mode or by continues rotation mode.

a image plate picture (A17020)

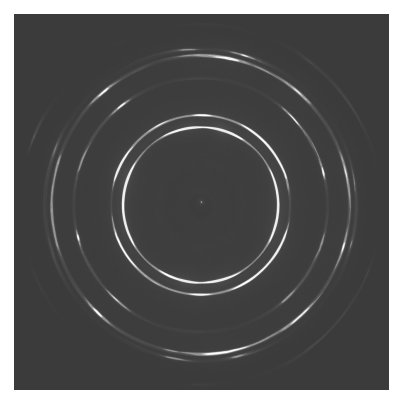

b one Debye-Scherrer-ring

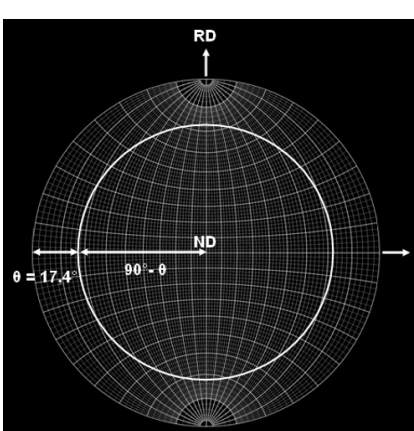

c pole figure coverage $d$ after sample rotation

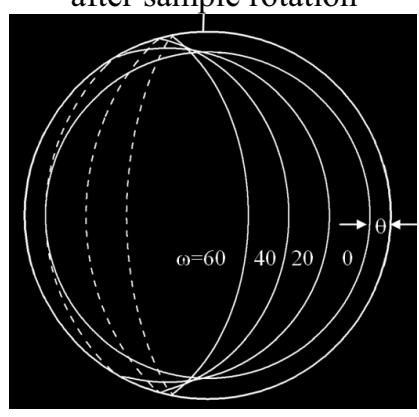

d (111) pole figure

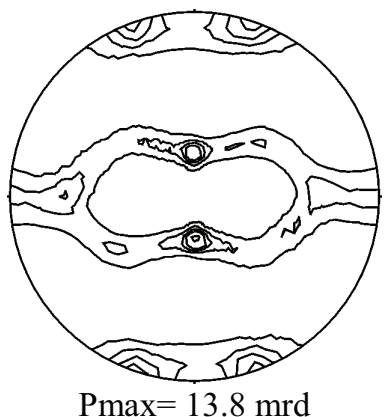

Fig.8: From area detector data to pole figures

a) area detector information for one sample position; b) information of one Debye-Scherrer ring inside a stereo graphic projection; c) needed sample rotations to cover pole figures;

d) (111) pole figure of rolled $\mathrm{Al}$

The following example describes the flexibility of synchrotron investigations for standard pole figure measurements, see fig 9, showing a steel shaft of $34 \mathrm{~mm}$ thickness (fig. 9a and 9b) and a thin Fe foil of $10 \mu \mathrm{m}$ thickness [14]. That means in practice, one needs a set of special sample holders.

a

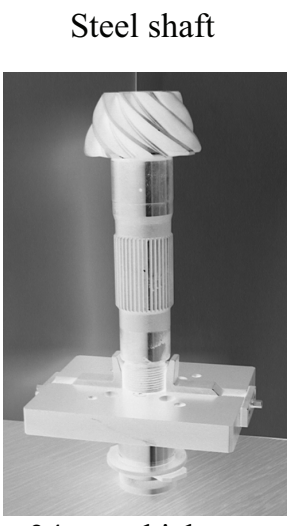

$\mathrm{b}$

(110) pole figure steel shaft

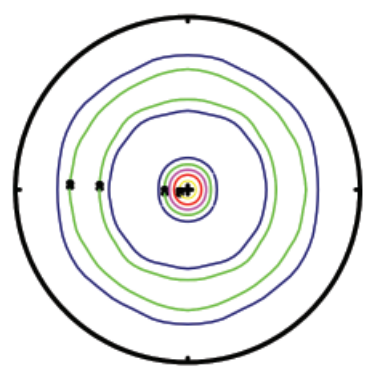

$P \max =1.9 \operatorname{mrd}$ c Fe foil

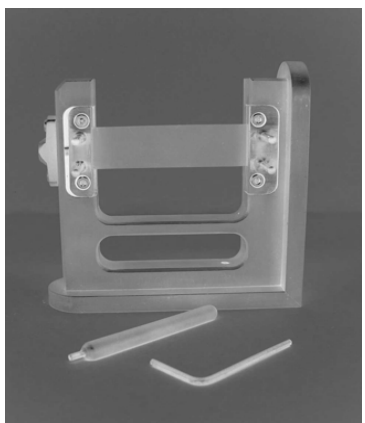

$10 \mathrm{~mm}$ thickness d (110) pole figure Fe foil

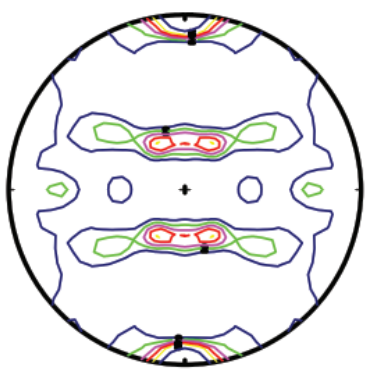

$\operatorname{Pmax}=12.5 \mathrm{mrd}$

Fig.9: Steel shaft of $34 \mathrm{~mm}$ thickness (a) with (110) pole figure (b); Fe- foil of $10 \mu \mathrm{m}$ thickness(c) with (110) pole figure (d)

Despite the possibility to measure large samples it is a common way to analyse partly prepared samples to get texture gradients after in homogeneous. Samples were cut to have the texture gradient along a z-axis as shown in fig. 10 [15]. Typical examples are texture gradients in ECAP [16], HPT samples or texture gradients over welds. The investigation of inhomogeneities and gradients are also used to understand acentricities and variations of wall thicknesses in pipes and tubes (fig 10b). Moreover, gradient investigations of tensile samples after failure (fig. 10c) or extrusion profiles have been analyzed. 


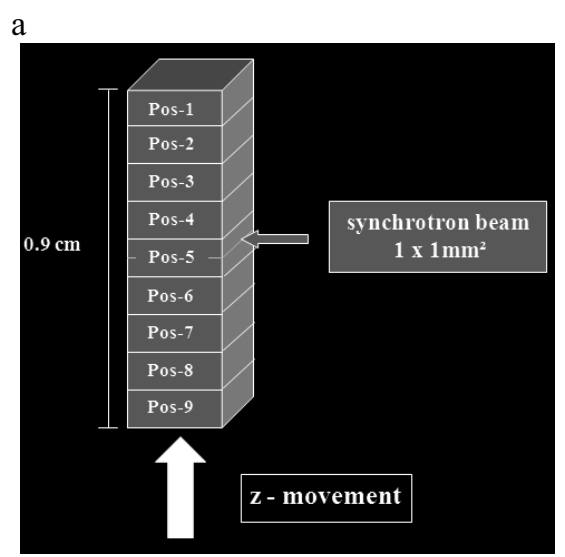

b stack of samples from a Cu-tube



$\mathrm{c}$

Tensile sample after failure

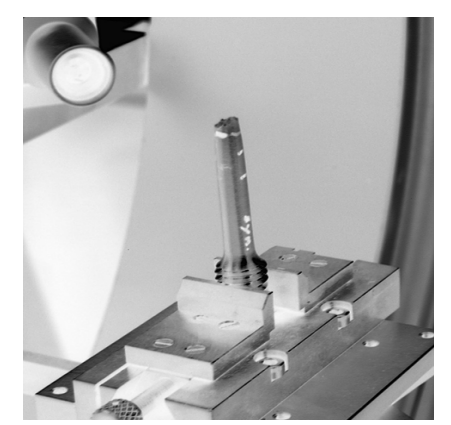

Fig.10: Texture gradient investigations using $1 \times 1 \mathrm{~mm}$ synchrotron; a) $\mathrm{z}$-scan along the gradient, b) stack of samples prepared from a Cu-tube, c) tensile sample after failure.

Recent measurements on Al7020 have shown that complete pole figure measurements of about $6 \mathrm{Al}$ reflections can be carried out in $30 \mathrm{sec}$. That opens the field of in situ investigations under different thermo-mechanical treatments such as dynamic processes.

\section{Conclusions}

Hard X-rays (photons) and thermal neutrons are excellent to measure texture, phase composition and strain non-destructively. Both radiations have a high penetration power to investigate bulk properties as well as gradient properties. Neutron diffraction is favoured for larger gauge volume and and coarse grained materials. The comparison of tensile properties and diffraction data on identical samples is possible. Due to used wavelength the $90^{\circ}$ arrangement allows sample rotation and sample tilt with less deviation in gauge volume. Photons with high energies have similar penetration powder than neutrons but photon flux and brilliance are much higher. Due to the beam quality, beamlines for medium grain size and very small grain sizes complement each other. The photons are favoured for much smaller gauge volume and precise gradient investigations.

New instrumentation was especially dedicated to materials science applications. Stress-Spec is a very flexible neutron diffratometer recently equipped with a robot to carry heavy samples with complex sample geometries. 2010 the new HEMS beamline starts operation which is the high brilliance materials science diffractometer at Hasyslab.

It should be noticed that both radiations are also excellent for in situ studies which is not the topic of this contribution.

\section{Acknowledgement:}

The work has been funded by the German Ministry of Education and Research (BMBF) under the contract number $05 \mathrm{KN} 7 \mathrm{MCA}$. 


\section{References}

[1] W.Reimers, A. Pyzalla, A. Schreyer, H. Clemens: Neutrons and Synchrotron Radiation in Engineering Materials Science (Wiley VCH, Weinheim, Germany 2008).

[2] H.-G. Brokmeier: Physica B: Condensed Matter Vol. 385 (2006), p. 623.

[3] T. Lorentzen, M.T. Hutchings, P.J. Withers: Introduction to Characterization of Residual Stress by Neutron Diffraction (Taylor and Francis, London, 2005)

[4] S. F. Nielsen, A. Wolf, H. F. Poulsen, M. Ohler, U. Lienert, R. A. Owen,: J. Synchrotron Rad. Vol. 7 (2000), p. 103.

[5] H.-G. Brokmeier, W. M. Gan, C. Randau, J. Rebelo-Kornmeier, M. Hofmann: Nuclear Instruments and Methods in Physics A: Vol. 642 (2011), p. 87.

[6] M. Hofmann, J. Robelo-Kornmeier, U. Garbe, R.C. Wimpory, J. Repper, G.A. Seidl, H.-G. Brokmeier, R. Schneider: Neutron News Vol. 18 (2007), p. 27.

[7] C. Randau, U. Garbe, H.-G. Brokmeier: J. Appl. Cryst. Vol. 44, (2011), p. 641.

[8] H.J. Bunge, H. Klein: Z.Metallkunde Vol. 87 (1996), p.465.

[9] H.-G. Brokmeier: Proc. ICOTOM12, edited by J. A. Szpunar, NRC Research Press, Ottawa, Canada 1999, p. 86.

[10] H.-G. Brokmeier, C. Randau, U. Garbe, P. Spalthoff, J. Bohlen: Proc. $8^{\text {th }}$ Int. Conf. on Magnesium Alloys and their Applications, Wiley-VCH, Weinheim, Germany 2009, p. 583.

[11] A. King, M. Herbig, W. Ludwig, P. Reischig, E.M. Lauridsen, T. Marrow, J.Y. Buffière: Nuclear Instruments and Methods in Physics B: Vol. 268 (2010), p. 291.

[12] J.F.H. Clusters: Philips Techn. Rundscahu Vol. 7 (1942), p.13

[13] H.R. Wenk, Schweiz. Min. Petr. Mitt. (1966), p. 518.

[14] H.-G. Brokmeier, S.B. Yi, J. Homeyer, in: Microstructure and Texture in Steels, edited by A. Haldar, S. Suwas, D. Bhattacharjee, Springer Verlag, London, UK (2009) p. 307.

[15] H.-G. Brokmeier, A. Günther, S. Yi, W. Ye, T. Lippmann, U. Garbe: Advances in X-ray Analysis Vol. 46 (2003), p. 151.

[16] W. Skrotzki, N. Scheerbaun, C.-G. Oertel, H.-G. Brokmeier, S. Suwas, L.S. Toth: Acta Mater. Vol. 55 (2007), p. 2211. 


\section{Textures of Materials}

10.4028/www.scientific.net/MSF.702-703

Investigation of Texture Gradients of Semi-Finished Products by Neutrons and Photons

10.4028/www.scientific.net/MSF.702-703.499 